\title{
Considerations for the Use of Minimally Invasive Aesthetic Procedures for Facial Remodeling in Transgender Individuals
}

\author{
Koenraad De Boulle (D) \\ Nobutaka Furuyama (iD) ${ }^{2}$ \\ Izolda Heydenrych (iD ${ }^{3,4}$ \\ Terrence Keaney ${ }^{5}$ \\ Alexander Rivkin ${ }^{6}$ \\ Vincent Wong (iD ${ }^{7}$ \\ Michael Silberberg ${ }^{8}$ \\ 'Aalst Dermatology Clinic, Aalst, \\ Belgium; ${ }^{2}$ Jiyugaoka Clinic, Medical \\ Corporation, Tokyo, Japan; ${ }^{3}$ Cape Town \\ Cosmetic Dermatology Centre, Cape \\ Town, South Africa; ${ }^{4}$ Division of \\ Dermatology, Faculty of Health Sciences, \\ University of Stellenbosch, Stellenbosch, \\ South Africa; ${ }^{5}$ SkinDC, Arlington, VA, \\ USA; ${ }^{6}$ Westside Aesthetics, Los Angeles, \\ CA, USA; ${ }^{7}$ Vindoc Aesthetics, London, \\ UK; ${ }^{8}$ Allergan Aesthetics, an AbbVie \\ Company, Marlow, Buckinghamshire, UK
}

Correspondence: Koenraad De Boulle Aalst Dermatology Clinic, 43 Leopoldlaan, Aalst, 9300, Belgium Tel +3253781899

Fax +325377/915

Email koen@doctordeboulle.be

\begin{abstract}
There is increasing demand among transgender individuals for minimally invasive aesthetic procedures, such as injectable facial fillers and neurotoxins, for facial remodeling and transformation. These procedures may increase transgender individuals' satisfaction with their appearance and allow them to more effectively harmonize their physical appearance with their perception of self. There is currently a lack of information in the medical literature regarding guidelines for the use of these products in transgender patients. In this report, the authors provide experience-based treatment considerations and recommendations for use of minimally invasive facial aesthetic procedures in transgender patients, including case studies illustrating the use of these procedures for both male-to-female and female-tomale transitioning patients. This report highlights the success of minimally invasive methods for assisting transgender patients in achieving their facial remodeling goals. Clinicians play an integral role in the transitioning process for transgender patients, and facial transformation is a key element of this process. When conducted with sensitivity and attention to individual patient goals at varying stages of transition, facial procedures can be of great benefit in enhancing patients' self-perception and overall quality of life.
\end{abstract}

Keywords: transgender persons, hyaluronic acid, neurotoxins

\section{Introduction}

The proportion of individuals who identify as transgender or gender-diverse ranges from $0.1 \%$ to $2.7 \%$ depending on the age, inclusion criteria, and geographic location. ${ }^{1}$ Among these individuals, there is increasing demand for minimally invasive aesthetic procedures, such as injectable facial fillers and neurotoxins, for facial transformation. ${ }^{2,3}$ Transgender individuals may seek facial aesthetic modifications during their transitioning process by considering ideals that relate to looking more feminine or masculine. ${ }^{4,5}$ They want their outward appearance - the face they present to the world - to reflect how they feel about themselves. ${ }^{4}$

Differences between masculine and feminine faces have a hormonal basis: high estrogen levels result in high cheekbones, a proportional nose, full lips, as well as a relatively small and narrow chin, whereas high testosterone levels result in prominent supraorbital ridges, linear eyebrows, a flat midface, a more prominent nose, thin lips, and a squared jawline with a strong chin. ${ }^{6}$ Some transitioning patients receive hormonal therapy and gender-affirmation surgery, with the most dramatic changes in facial anatomy achieved through surgery. However, the use of minimally invasive facial aesthetic procedures may increase transgender 
individuals' satisfaction with their appearance and yield aesthetic enhancements that meet desired feminizing or masculinizing goals as patients start or complete their transition. ${ }^{5,7}$ A number of transgender individuals identify with the traditional binary notions of gender; however, some individuals do not identify with the classic binary gender roles and may choose to be gender-diverse or to express themselves somewhere on the spectrum between feminine and masculine; ${ }^{8}$ they do not want to look vaguely feminine or masculine, preferring instead to pass as their self-identified gender. ${ }^{4}$ Minimally invasive procedures such as botulinum toxin, injectable fillers, skin resurfacing, and topical skin care products are essential in this regard, accomplishing the fine detail work necessary not only to transition to feminine or masculine faces, but also for selfaffirmation. These procedures complement the structural changes accomplished by surgery, smoothing overly sharp transitions, softening edges, and filling in details.

The medical literature on the transgender use of fillers, toxins, and other minimally invasive aesthetic procedures is currently lacking. ${ }^{4,9}$ A review of the existing literature indicated that the most-studied transgender research topic was "therapeutics and surgeries," with the majority of the research in this area focusing on case studies investigating issues such as outcomes of surgeries, hormone treatments, and silicone injections. ${ }^{10}$ Although high interest exists for the technical aspects of surgery on the sexual organs, there is dramatically less interest among the medical community in the transition of facial characteristics. ${ }^{10}$ Thus, there is a need to develop treatment plans and recommendations for minimally invasive aesthetic procedures. These procedures help to achieve the facial transformation goals of transgender patients, including matching outward appearance with self-perception, ultimately improving their quality of life. ${ }^{7}$

\section{Part I: Considerations for Facial Aesthetic Modifications in Transgender Patients Optimal Care for the Transgender Patient} Although transgender patients may seek feminizing or masculinizing effects, the clinician must be aware that aesthetic preferences of transgender individuals may not conform to traditional binary standards of facial beauty. ${ }^{7}$ A key element of transgender aesthetic goals may not be achievement of femininity or masculinity itself, but rather acquiring feminine or masculine attributes that align with the patient's self-affirmation; transgender individuals commonly seek aesthetic procedures to avoid being misgendered or identified incorrectly. The goals of transgender patients may also be associated with the desire to convey certain positive character attributes with associated social, professional, cultural, and economic advantages. ${ }^{6}$

Transgender patients seeking minimally invasive injectable procedures should receive personalized initial consultation and follow-up, with instruction that maintenance treatments will be required to retain physical changes provided by these procedures. ${ }^{5}$ Maintenance is extremely important to preserve the desired and achieved facial features, but patients must also appreciate the economic consequences of repeated facial treatments. ${ }^{2}$ Because the lack of or reduced insurance coverage for aesthetic procedures in many countries may create limitations for some patients, clinicians may need to help patients prioritize their aesthetic goals., ${ }^{9,11}$

Understanding the aesthetic concerns and psychological well-being unique to the transgender population is important for providing optimal patient care. $^{12}$ Transgender patients may experience "gender dysphoria" or distress about their assigned sex at birth. ${ }^{12}$ Inclusive and compassionate patient communication is key when working with transgender patients and managing treatment expectations. Clinicians should also realize that communication may differ between transgender and cisgender male/female patients. Staff should be trained to address transgender patients using the patients' preferred pronouns and identifiers, and intake forms should request information about "gender" rather than "sex," with a write-in option for "other." The authors also recommend selfreflection for clinicians to ensure their own comfort with and acceptance of transgender patients before working with them, as well as improved professional training for healthcare providers to better understand and address the healthcare needs of transgender patients. ${ }^{13}$ Otherwise, a lack of compassion or acceptance may subtly emerge during patient interactions, possibly to the detriment of patients' psychological well-being.

Clinicians should be aware of and sensitive to the different steps of the transition process that transgender patients may undergo, understanding that the transition process is fluid and ongoing, with patients often needing to "grow into" their new looks. ${ }^{11,14}$ There are currently no formal guidelines regarding the timing of when during the transition process of facial feminization or masculinization nonsurgical procedures should occur. Many physical changes 
resulting from hormone therapy do not fully develop until 2 years after therapy initiation. ${ }^{4}$ Patients may therefore be seeking aesthetic facial procedures at various stages during the process, from those who have not yet started hormone therapy because they are still exploring the idea, to those who have been on hormone therapy for less than 6 months, for 6 to 18 months, or for many years. The needs and expectations of patients at each stage will be different, and treatment approaches should take into account the significant changes in facial structure, soft tissue distribution, and skin quality brought about over time by hormonal therapy. ${ }^{5,7}$

\section{Facial Aesthetic Goals for Transitioning Individuals}

Customized treatment approaches and recommendations for facial remodeling using minimally invasive injectable procedures in transgender patients should consider the following principles and practices. It is important to recognize that there are different goals related to what constitutes "female" and "male" faces (Table 1; Figure 1). ${ }^{9,15}$ In general, female features are characterized by an ovalshaped face; smooth, convex forehead; laterally peaked eyebrows above the superior orbital rim; wide, openappearing eyes; narrow, concave nose; prominent cheeks positioned more superior and lateral; flat or slightly convex temples; obtusely angled jaw; smaller pointed chin; and fuller lips. ${ }^{3,16-19}$ Male facial features, in contrast, are generally characterized by a square-shaped face, straight eyebrows, a strong well-proportioned nose, cheeks that are not that rounded or prominent (with the cheek apex positioned more inferior and medial), a well-defined and prominent jaw, and equally balanced upper and lower facial proportions. ${ }^{20}$

Each area of the face (upper, middle, and lower) has distinctly feminine or masculine features that together affect gender perception., ${ }^{5,21}$ For the upper face, the approximately $20 \%$ larger cranium in males relative to females lends males a broader forehead, flattening above the eyebrows and sloping toward the hairline. ${ }^{5,16}$ Male eyebrows are flat and rest on or below the more prominent supraorbital ridge, whereas the female forehead (rounded, with a mild forward projection) slopes smoothly into the orbit. ${ }^{16,22-24}$ Female eyebrows arch in the lateral-third aspect over a subtle supraorbital ridge, and the orbit is oval. $^{22,25,26}$ The female temple area can also be slightly convex, whereas the male temple is flat to slightly concave. ${ }^{9,19}$

Regarding the middle face, the male nose is broader and straighter than the narrow female nose, which is characterized by a supratip break that is elevated by an inflection point on the dorsum before the nasal tip. The nasolabial angle in males is 90 to 95 degrees, compared with 95 to 105 degrees in females. ${ }^{27}$ The male nasofrontal angle is sharper than the female $\left(130^{\circ}\right.$ vs $\left.134^{\circ}\right) .{ }^{16}$ In addition, males have a broader, flatter malar prominence over a wider frontal and zygomatic process, whereas the female cheek is better defined with greater anterior projection. $^{28}$ The female zygomatic projection is also greater relative to the lateral projection of the mandibular angle, giving female faces a tapered appearance in contrast to the square shape of the male face. ${ }^{19}$ Magnetic resonance imaging studies of soft tissue distribution have shown that the mean thickness of the medial cheek in a female face is

Table I Facial Aesthetic Goals for Transitioning Individuals 9,15

\begin{tabular}{|c|c|}
\hline Ideal Female Face & Ideal Male Face \\
\hline Large, smooth forehead with some convexity and arched eyebrows & Wider forehead with horizontal brow and prominent supraorbital ridge \\
\hline Eyes that appear wide open & Deeper-set eyes that appear close together \\
\hline Proportionally smaller, narrow nose with upturned nasal tip & Proportionally larger, wider, more projected nose \\
\hline Obtuse nasofrontal angle & Less obtuse nasofrontal angle \\
\hline Obtuse nasolabial angle & Less obtuse nasolabial angle \\
\hline Heart-shaped taper in lower face with smaller lower-to-upper face ratio & More equal ratio of lower-to-upper face proportions \\
\hline Prominent, full cheeks and cheekbones & Squared lower face and jaw \\
\hline Full lips, especially anteroposterior axis & Wider mouth with thinner lips \\
\hline Rounded, narrow, proportionally short chin & Long, square, flat chin \\
\hline
\end{tabular}


Ideal Female Face

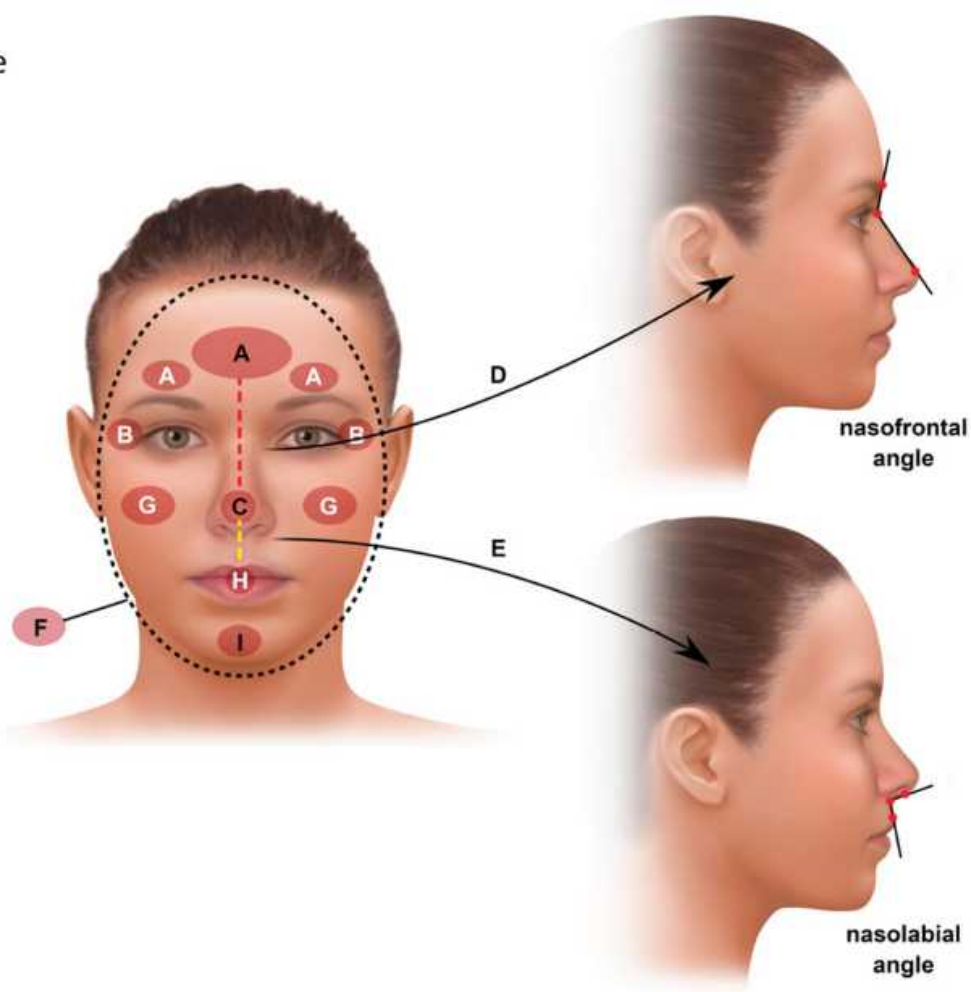

Ideal Male Face

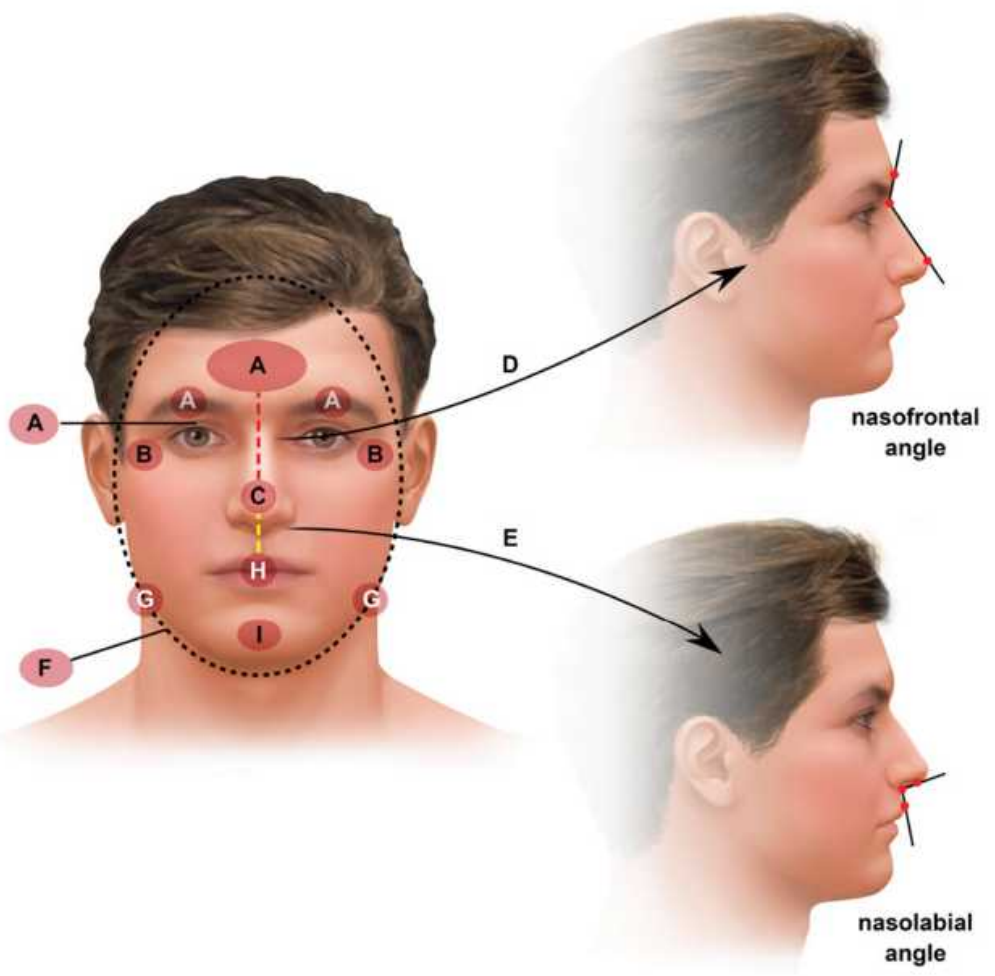

Figure I Schematic of facial aesthetic goals for transitioning individuals. Based on Table I, the ideal female face has the following features: (A) Large, smooth forehead with some convexity and arched eyebrows, (B) Eyes that appear wide open, (C) Proportionally smaller, narrow nose with upturned nasal tip, (D) Obtuse nasofrontal angle, (E) Obtuse nasolabial angle, (F) Heart-shaped taper in lower face with smaller lower-to-upper face ratio, (G) Prominent, full cheeks and cheekbones, (H) Full lips, especially anteroposterior axis, and (I) Rounded, narrow, proportionally short chin. The ideal male face has the following features: (A) Wider forehead with horizontal brow and prominent supraorbital ridge, (B) Deeper-set eyes that appear close together, (C) Proportionally larger, wider, more projected nose, (D) Less obtuse nasofrontal angle, (E) Less obtuse nasolabial angle, (F) More equal ratio of lower-to-upper face proportions, (G) Squared lower face and jaw, (H) Wider mouth with thinner lips, and (I) Long, square, flat chin. 
approximately $50 \%$ greater than the lateral cheek (15.9 vs $10.9 \mathrm{~mm}$ in young women), whereas the soft tissue is more evenly distributed in the male face. ${ }^{29,30}$

In the lower face, males have an overall squared-off angularity, ${ }^{5,27}$ including larger masseter muscles and a broader mandible anterolaterally, with a prominent flexure at the mandibular ramus. ${ }^{31}$ The male chin is also wider, larger, and flatter with increased anterior projection. ${ }^{20,32}$ The female face overall has a more tapered silhouette and a triangular, heart-shaped structure, with a smaller chin and jawline. ${ }^{5}$ The female chin is more rounded in shape with less anterior projection, versus the more square male chin, and feminine lips tend to be more full. ${ }^{19}$

\section{Part 2: Technical Recommendations for the Use of Minimally Invasive Injectable Procedures for Facial Remodeling in Transgender Patients}

With support from existing literature, the authors offer several treatment recommendations using injectable fillers and toxins for when an assigned male or female at birth is feminizing or masculinizing, respectively (Table 2). When the individual is transitioning from male to female (ie, transwoman), larger doses of both fillers and toxins may be required because facial skin and muscle mass tend to be thicker in cisgender males than in females. ${ }^{33,34}$ Based on these inherent genetic differences, more frequent maintenance injections of toxin may also be needed for patients undergoing male-to-female transition ${ }^{9}$ to maintain an appearance that communicates youthfulness and femininity. ${ }^{35}$ In addition, the type of product and doses for medical aesthetic treatments will need adjustment depending on the patients' stage of the transition process and the time-dependent effects of hormonal therapies, as discussed above. ${ }^{7}$

The perception of what constitutes an ideal male or female face is also influenced by race and ethnicity. Unique differences in skin physiology, aging mechanisms, and craniofacial anatomy have been described extensively. ${ }^{36-38}$ Clinicians should be sensitive with respect to unique racial and ethnic features when performing facial remodeling in transgender patients. In general, culture- and ethnic-specific aesthetic treatment goals should be respected. ${ }^{36,39}$ Clinicians need to be aware of their subliminal biases relating to race, gender, and sexual orientation, which can affect patient care. $^{40}$
Comprehensive training related to cultural competence and humility training, in addition to clear communication with the patient, can help ensure that clinician bias does not affect the treatment plan. ${ }^{40}$ After careful communication regarding the patient's preferences, each treatment plan is uniquely tailored to the individual.

When performing injectable facial remodeling procedures in transgender patients, clinicians should consider different injection sites and properties of dermal fillers and toxins. Injection sites for fillers include the zygomaticomalar region, anteromedial cheek, nose, and submalar regions, as well as chin, jawline, temples, supra-orbital brow, forehead, tear trough, nasolabial folds, and melomental folds. ${ }^{5,34,41}$ Clinicians should consider the rheologic properties of fillers when selecting the most appropriate filler for the desired outcomes. For proper placement of toxins with a genderizing approach as the goal, it is often necessary to adjust the distribution and placement of injections outside of standard injection points. For example, being more conservative with injections in the frontalis muscle in men can prevent eyebrow ptosis. ${ }^{34}$ In addition, retaining frontalis muscle activity above the lateral one-third of the brow can lift the eyebrow, providing a feminine arched eyebrow. ${ }^{9}$ Consideration should also be given to smoothing the skin for males transitioning to females, such as decreasing pore size and fine lines, as well as improving skin tightness, using lasers, peels, and cosmeceuticals because smooth skin looks younger and thus more fertile and feminine. ${ }^{35,42}$

\section{Case Studies: The Use of Fillers and Toxins in the Transitioning Transgender Population}

The authors provided several case studies illustrating the use of minimally invasive facial remodeling procedures for both male-to-female and female-to-male transitioning patients. The patients have provided written consent to the authors to publish their images and details. No institutional approval was required to publish the individual case details.

\section{Case Study \#I (Contributed by AR)}

Facial transformation in a 40-year-old male-to-female transgender patient (Figure 2). The patient received 12 units of onabotulinumtoxinA at the crow's feet lines to lift her eyebrows, 12 units in the glabella, and 8 units in the chin. She also received the HA dermal filler VYC-20L 
Table 2 Potential Uses of Injectable Fillers and Toxins for Facial Remodeling in Transitioning Individuals

\begin{tabular}{|c|c|c|}
\hline \multirow[b]{2}{*}{$\begin{array}{l}\text { Facial } \\
\text { Remodeling } \\
\text { Goals }\end{array}$} & \multicolumn{2}{|c|}{ Recommendations From Upper to Lower Face } \\
\hline & Dermal Fillers & Neuromodulators \\
\hline \multirow[t]{5}{*}{$\begin{array}{l}\text { Male to } \\
\text { Female }\end{array}$} & $\begin{array}{l}\text { Inject into forehead at the supraperiosteal level to help treat } \\
\text { deep furrows and achieve a smooth, gently convex } \\
\text { contour; }{ }^{20,43} \text { improve temporal fossa volume; } ;^{5} \text { camouflage } \\
\text { a prominent brow ridge, and help raise the lateral eyebrow } \\
\text { arch }^{43}\end{array}$ & $\begin{array}{l}\text { Inject into forehead, glabellar, or periorbital areas to eliminate } \\
\text { dynamic rhytids and create a more feminine forehead, angled } \\
\text { eyebrow shape, and widened eyes; }{ }^{5,9} \text { injection into the } \\
\text { superolateral orbital portion of the orbicularis oculi muscle } \\
\text { may raise the lateral brow, }{ }^{44,45} \text { whereas injection into the } \\
\text { palpebral portion of the orbicularis oculi may widen the eye } \\
\text { aperture, with injections placed inferior to the lower eyelid and } \\
\text { lateral to the midpupillary line }{ }^{43}\end{array}$ \\
\hline & $\begin{array}{l}\text { Inject along zygomatic arch to help cheeks appear more } \\
\text { prominent and contoured; inject into anterior malar area to } \\
\text { create a prominent, full, and more feminine apex peaking more } \\
\text { superiorly and laterally,9 }\end{array}$ & $\begin{array}{l}\text { Atrophy the glabellar musculature to help create a more } \\
\text { obtuse nasofrontal angle; }{ }^{5} \text { weaken the depressor septi nasi } \\
\text { muscle to feminize the nose by lifting the nasal tip; weaken the } \\
\text { nasal alar muscles to decrease alar flare }\end{array}$ \\
\hline & $\begin{array}{l}\text { Inject medially into chin to give it a more-rounded, less-square } \\
\text { contour }\end{array}$ & $\begin{array}{l}\text { Inject into the masseter and mentalis muscles to cause gradual } \\
\text { atrophy, decreasing the prominence of the male jawline and } \\
\text { making the face appear more heart shaped }{ }^{44,46}\end{array}$ \\
\hline & $\begin{array}{l}\text { Inject into lips to augment them }{ }^{9} \text { and into the perioral region } \\
\text { to improve lip contour and decrease rhytids }{ }^{47}\end{array}$ & \\
\hline & $\begin{array}{l}\text { Address signs of aging such as temple volume loss, marionette } \\
\text { hollowing, prejowl sulcus, and tear trough development }\end{array}$ & \\
\hline \multirow[t]{4}{*}{$\begin{array}{l}\text { Female to } \\
\text { Male }\end{array}$} & $\begin{array}{l}\text { Inject into supraorbital ridge to increase brow line } \\
\text { prominence }^{5}\end{array}$ & \multirow{4}{*}{$\begin{array}{l}\text { Inject into the medial and lateral frontalis to help cause an } \\
\text { arched brow to drop, resulting in a more masculine } \\
\text { appearance }^{5}\end{array}$} \\
\hline & $\begin{array}{l}\text { Inject uniformly along the zygomatic arch, inferior and medial } \\
\text { to the malar prominence, to help broaden the malar base and } \\
\text { reduce anterior projection of the apex }\end{array}$ & \\
\hline & $\begin{array}{l}\text { Inject at various points along the radix, dorsum, sidewall, tip, } \\
\text { and columella to help broaden the nose },{ }^{5} \text { widen the nasal tip, } \\
\text { create a dorsal bump, and narrow the nasofrontal and } \\
\text { nasolabial angles }\end{array}$ & \\
\hline & $\begin{array}{l}\text { Inject into the chin, jawline, mandibular angle, and preauricular } \\
\text { area to help define the jaw, enhance the angle of the mandible, } \\
\text { and create a more prominent, square, and angular lower part } \\
\text { of the face } 5,48,49\end{array}$ & \\
\hline
\end{tabular}

for left temple hollow filling $\left(1.5 \mathrm{~cm}^{3}\right)$, malar and zygomatic augmentation $\left(2 \mathrm{~cm}^{3}\right)$, nonsurgical rhinoplasty to straighten the nose $\left(0.5 \mathrm{~cm}^{3}\right)$, and chin sculpting $\left(1.5 \mathrm{~cm}^{3}\right)$. The patient also underwent lip augmentation with $1 \mathrm{~cm}^{3}$ of HYC-24L. The outcome for this patient was a subtle feminization of her face. Midface volumization brought the cheek apex into a more superolateral position, creating a soft and feminine ogee curve, as well as a more oval shape to the face. Brow elevation gave her a slight arch to the lateral one-third of her eyebrow. Her nose became smoother, straighter, and more delicate via tip elevation and camouflage of the dorsal hump. Lastly, the lower face was feminized by lip augmentation, as well as tapering and narrowing of the chin.

\section{Case Study \#2 (Contributed by VW)}

Full-face transition in a 25 -year-old male-to-female transgender patient (Figure 3). This patient, who had been on estrogen therapy for over 2 years, received 4 units of onabotulinumtoxinA at each lateral end of her eyebrows 

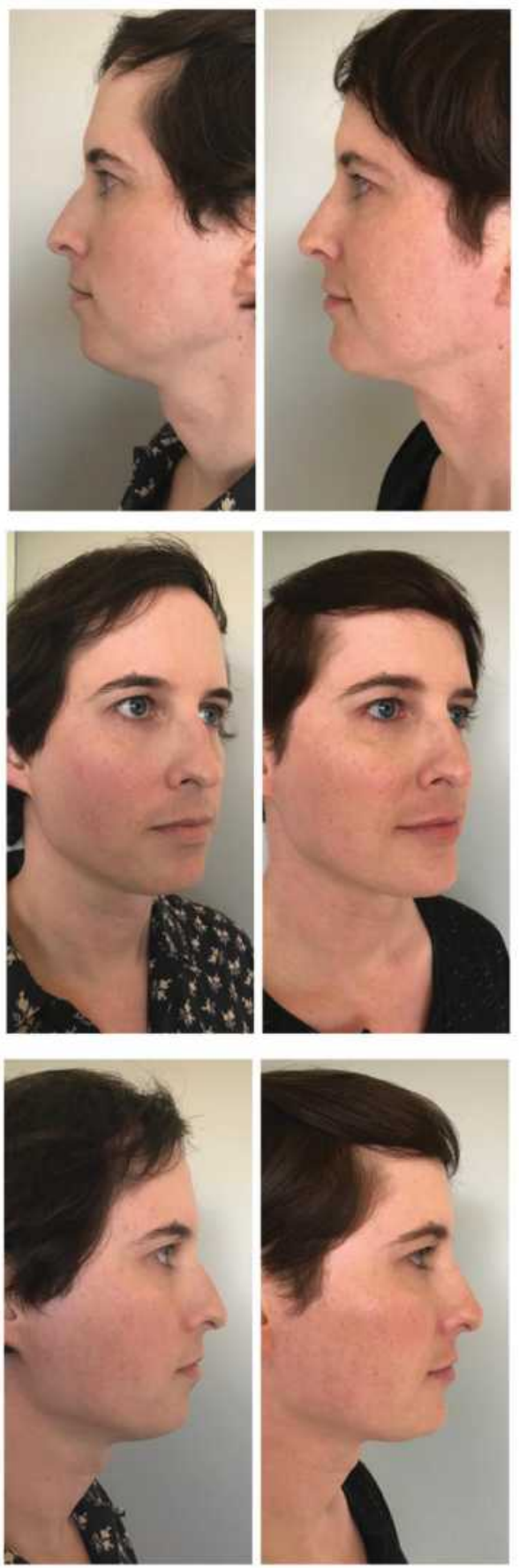
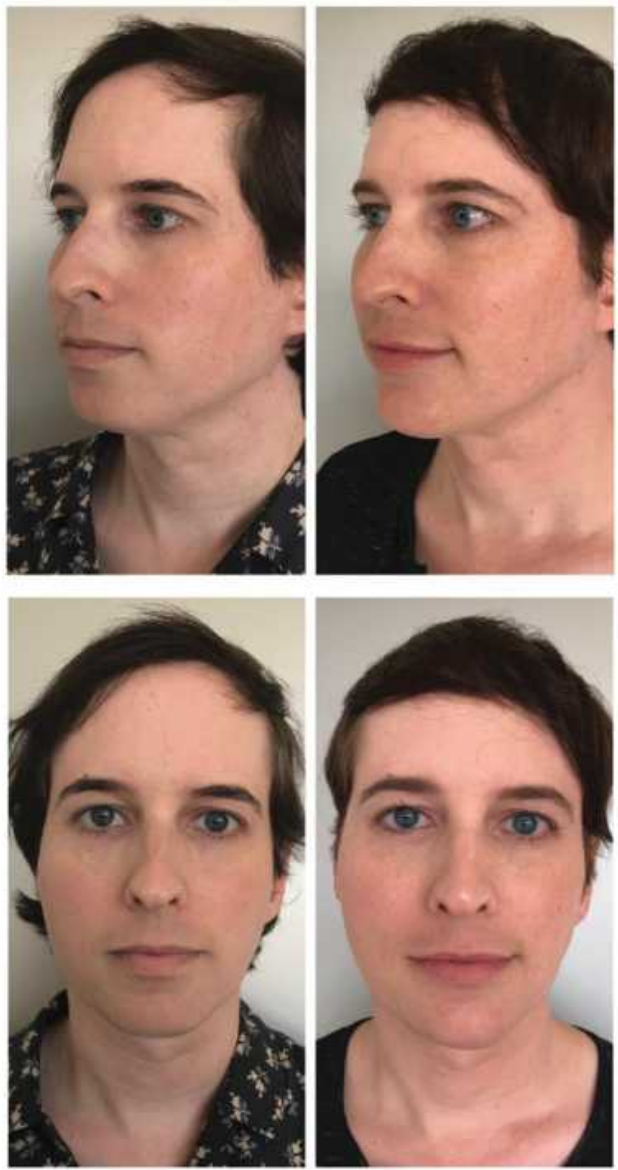

Figure 2 Facial transformation in a 40-year-old male-to-female transgender patient who received onabotulinumtoxinA and dermal fillers to feminize the face. Photographs were taken 2 months post-treatment. Patient images provided by Alexander Rivkin, MD.

to lift them and 25 units in each masseter to reduce the muscle bulk. She received VYC-20L at each temple $\left(1 \mathrm{~cm}^{3}\right)$ to correct for hollowing, in the forehead $\left(1.2 \mathrm{~cm}^{3}\right.$ total $)$, at each alar base $\left(0.3 \mathrm{~cm}^{3}\right)$, in the malar and zygomatic region for augmentation $\left(1.8 \mathrm{~cm}^{3}\right.$ total), and in the chin $\left(3 \mathrm{~cm}^{3}\right)$. Lip augmentation was also carried out using $1 \mathrm{~cm}^{3}$ of VYC-15L. The outcome for this patient was convexity of the forehead with diminished supraorbital bossing and brow elevation with improved convexity to the brow. In the midface, the cheeks were more pronounced with an enhanced ogee curve, and the nose base was more feminine. Her jawline became more $\mathrm{V}$ shaped with a feminine chin. Her lips were more heart shaped, which fit in with a more feminine visage. 

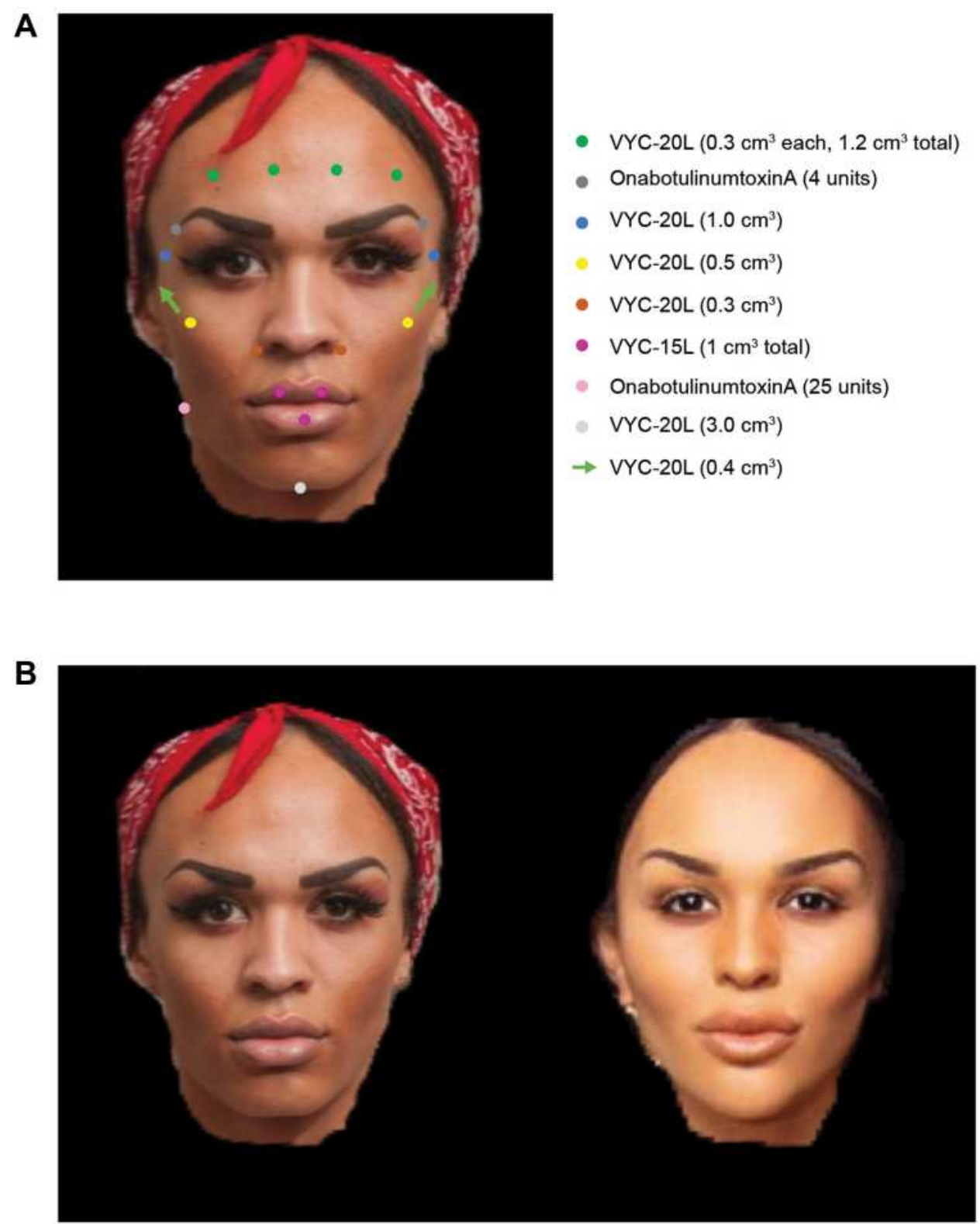

Figure 3 Full-face transition of a 25-year-old male-to-female transgender patient who received onabotulinumtoxinA and dermal fillers to feminize the face. (A) Colored dots and arrows indicate injection points with corresponding concentrations of onabotulinumtoxinA or filler injected. (B) The patient before (left) and 3 months after (right) treatment. Patient images provided by Vincent Wong, MD.

\section{Case Study \#3 (Contributed by KDB)}

Masculinization of the jawline in a 42-year-old female-to -male transgender patient (Figure 4). This patient was at the beginning of the transition process and was eager to experience how female facial looks could be transformed into desired male features without surgery. During the first treatment, he received bilateral bolus injections of VYC-20L $\left(0.5 \mathrm{~cm}^{3}\right)$ to the posterior part of the gonial angle; injections were placed perpendicular to the mandibular bone. He also received bilateral injections of VYC-20L $\left(0.25 \mathrm{~cm}^{3}\right.$ per injection site); 1 injection point was in the prejowl sulcus on the mandibular bone, and the other injection point was at the tuberculum mentale. One month later, VYC-20L $\left(1 \mathrm{~cm}^{3}\right.$ per side $)$ was administered along the mandibular body using a $25 \mathrm{G}$ cannula; the entrance point was posterior and inferior to the foramen mentale directed along the bony rim toward the masseter insertion.

\section{Case Study \#4 (Contributed by VW)}

Female-to-male jawline and chin enhancement in a 19year-old patient (Figure 5). This patient had been receiving 
A

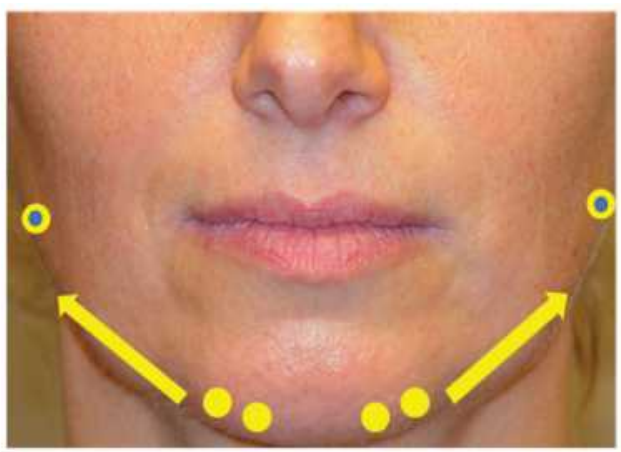

VYC-20L $\left(0.5 \mathrm{~cm}^{3}\right)$

VYC-20L $\left(0.25 \mathrm{~cm}^{3}\right)$

VYC-2OL $\left(1.0 \mathrm{~cm}^{3}\right)$
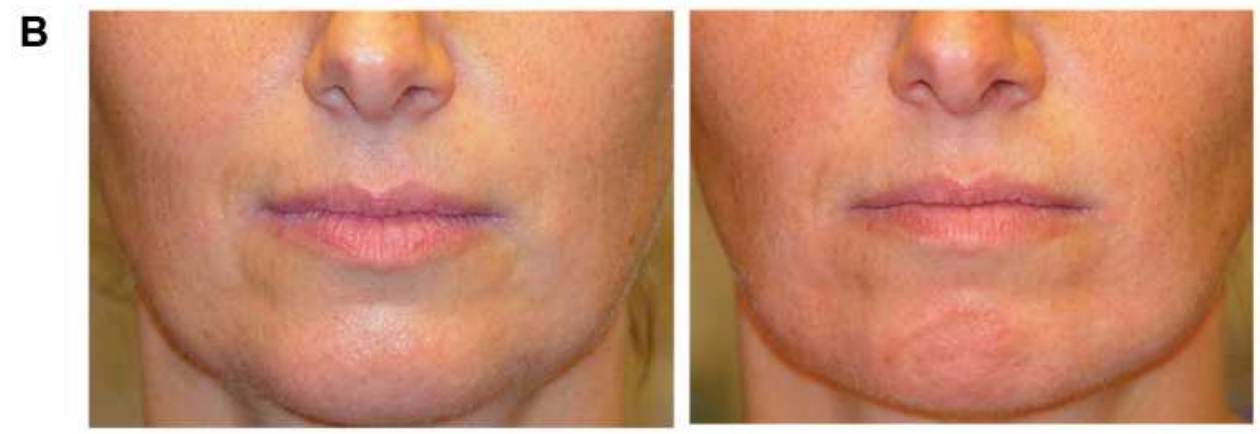

Figure 4 Masculinization of the jawline with repeated VYC-20L injections in a 42-year-old female-to-male transgender patient. (A) Colored dots and arrows indicate injection points with corresponding concentrations of filler injected. (B) The patient before (left) and 4 months after (right) treatment. Patient images provided by Koenraad De Boulle, MD.

testosterone for 7 months before undergoing nonsurgical lower face enhancement. A total of $6.2 \mathrm{~cm}^{3}$ of VYC-25L was distributed between the lateral lower chin, chin apex, submental region, mandible body, ramus of the mandible, and mandible angle. A masculine and well-defined jawline with prominent mandible angle was achieved. From the frontal view, the chin appeared broader and more square, in line with a masculine visage.

\section{Case Study \#5 (Contributed by TK)}

Feminization of the eyebrow using onabotulinumtoxinA in a patient in his late 20s (Figure 6). The patient presented to the clinic for treatment of the upper face rhytides. He received 10 units of onabotulinumtoxinA in the frontalis muscle. The injection pattern avoided the inferior frontalis muscle fibers in the lateral one-third of the eyebrow resulting in lateral eyebrow elevation. Two weeks after treatment, the patient developed a feminized eyebrow shape.

\section{Case Study \#6 (Contributed by TK)}

Feminization of the lips using HYC-24L in a patient in his early 60s (Figure 7). The patient received $1 \mathrm{~cm}^{3}$ of HYC$24 \mathrm{~L}$ in both the upper and lower lips to augment and shape his lips. Subtle augmentation was performed to highlight lip shape, especially the upper-lip Glogau-Klein points.

\section{Discussion}

Minimally invasive injectable procedures are an important complement to hormonal therapy and gender affirmation surgery for patients undergoing gender transition. These procedures allow the fine detail work necessary on the face to assist transgender patients in matching their outward appearance to how they perceive themselves. The importance of this aspect of the transition process is highlighted in the existing medical literature, including a survey-based assessment of 327 transgender individuals, which reported that facial modification was often a greater priority than other procedures on other body locations, especially for 
A

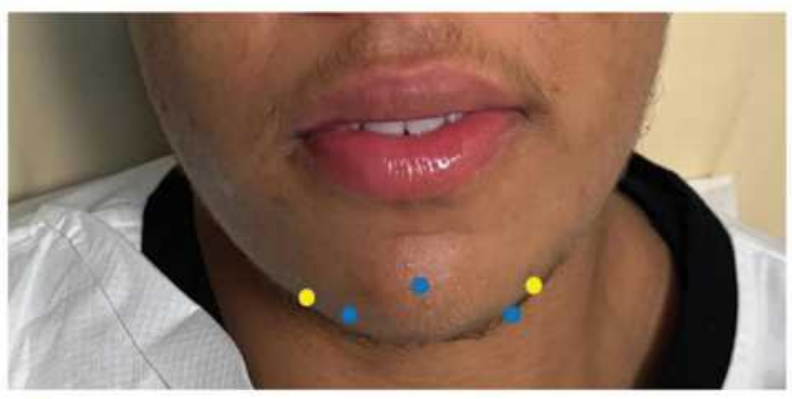

VYC- $25 \mathrm{~L}\left(0.4 \mathrm{~cm}^{3}\right)$

VYC- $25 \mathrm{~L}\left(0.2 \mathrm{~cm}^{3}\right)$

B

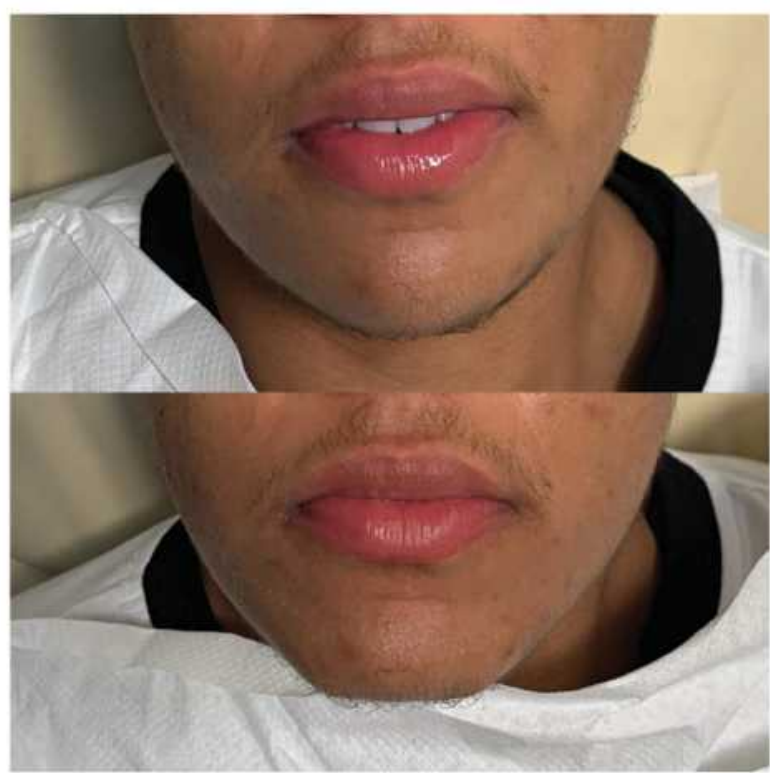

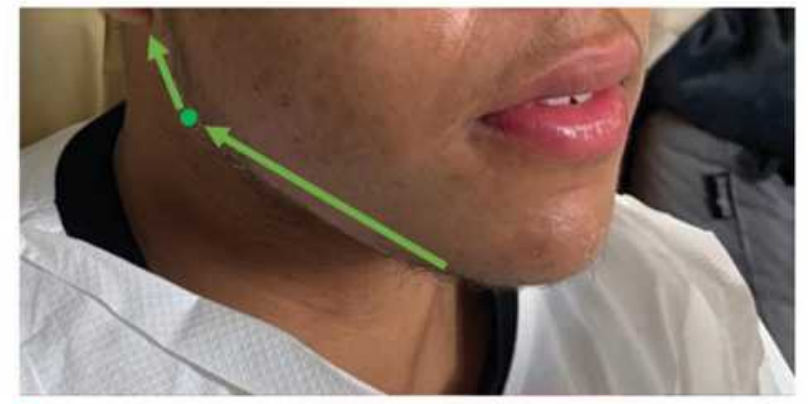

VYC- $25 \mathrm{~L}\left(0.8 \mathrm{~cm}^{3}\right)$

$\rightarrow$ VYC-25L $\left(1.0 \mathrm{~cm}^{3}\right)$ on body of mandible

VYC- $25 \mathrm{~L}\left(0.5 \mathrm{~cm}^{3}\right)$ on the ramus

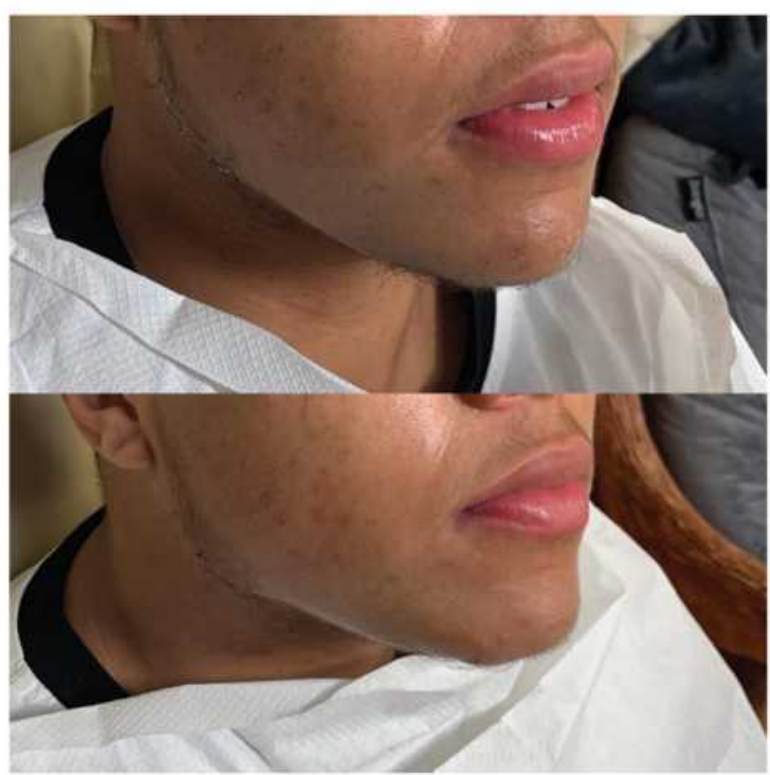

Figure 5 Female-to-male jawline and chin enhancement in a 19-year-old patient who received VYC-25L. (A) Colored dots and arrows indicate injection sites with corresponding concentrations of filler injected. (B) The patient before (top) and immediately after (bottom) treatment. Photographs were taken immediately following treatment. Patient images provided by Vincent Wong, MD.
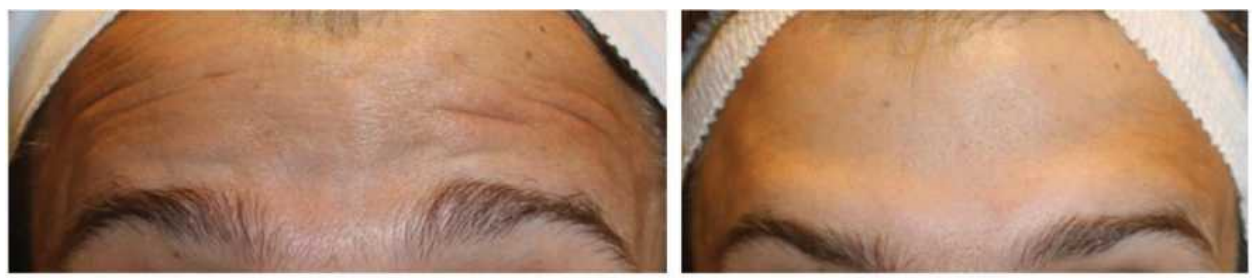

Figure 6 Feminization of the eyebrow using onabotulinumtoxinA in a patient in his late 20s. The patient before (left) and 2 weeks after (right) treatment. Patient images provided by Terrence Keaney, MD.

men transitioning into women. ${ }^{4}$ Some patients, especially those who have just embarked on their gender transition journey, appreciate a temporary, reversible modality such as injectables, which gives them the possibility to try out a more subtly feminine or masculine look prior to committing to the more permanent and dramatic changes of surgery. ${ }^{5}$ Furthermore, some transgender patients may not be ideal surgical candidates, and injectables may be the only option for their facial transformation. ${ }^{4}$ Subtle and effective changes can be achieved with minimally invasive 


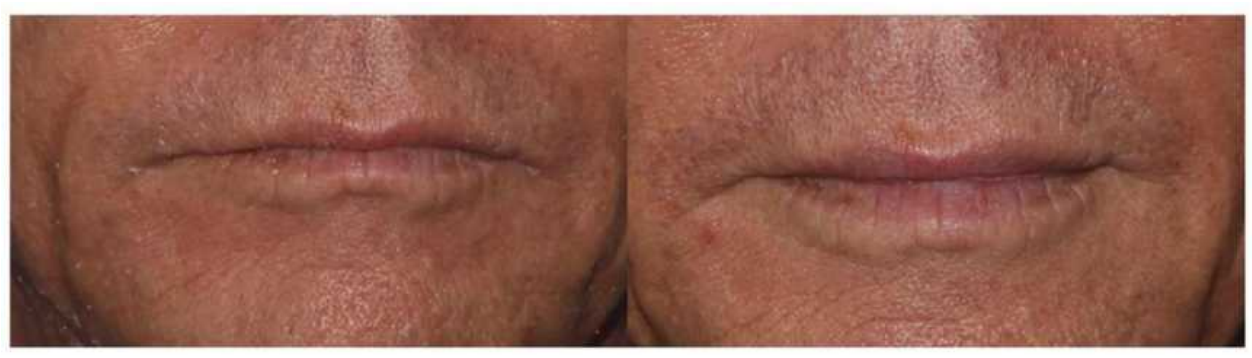

Figure 7 Feminization of the lips using HYC-24L in a patient in his early 60s. The patient before (left) and 2 weeks after (right) treatment. Patient images provided by Terrence Keaney, MD.

injectable procedures; these procedures can produce results with minimal risk and downtime, thus greatly aiding the transition process. ${ }^{4,9}$

\section{Conclusion}

This report highlights the success of minimally invasive methods for assisting transgender patients in their facial remodeling goals and in the progress of their transition journey. Clinicians play an integral role in the transitioning process for transgender patients, and facial transformation is a key element of this process.

\section{Acknowledgments}

Writing and editorial assistance was provided to the authors by Peloton Advantage, an Open Health company, Parsippany, NJ, and was funded by Allergan Aesthetics, an AbbVie Company, Irvine, CA, USA.

\section{Funding}

This research was funded by Allergan Aesthetics, an AbbVie Company, Irvine, CA, USA.

\section{Disclosure}

Dr. Koenraad De Boulle, Dr. Nobutaka Furuyama, Dr. Izolda Heydenrych, Dr. Terrence Keaney, Dr. Alexander Rivkin, and Dr. Vincent Wong have served as advisory board members (KDB, NF, IH, TK, AR), paid consultants (KDB, IH, VW), and/or investigators (TK, AR) for Allergan Aesthetics, an AbbVie Company, and have received honoraria (KDB, NF, IH, AR). Dr. De Boulle has also served as a paid consultant for Laboratoires Genévrier, Antibes, France. Dr. Keaney has also served as a speaker's bureau member for Allergan Aesthetics, an AbbVie Company, and has received personal fees from Merz, Galderma, Revance, and Evolus, outside the submitted work. Dr. Rivkin has also served as an advisory board member, investigator, and speaker for Merz (Frankfurt, Germany), Galderma (Lausanne, Switzerland), and Suneva Medical Inc. (San Diego, CA, USA). Dr. Wong has also served as a paid consultant for Relife Srl, a Menarini Group Company (Florence, Italy). Dr. Michael Silberberg is an employee of Allergan Aesthetics, an AbbVie Company, and holds stock shares. Dr. Furuyama is an advisory board member for, and has received honoraria from, Allergan Japan, an AbbVie Company. Editorial support for this article was provided by Peloton Advantage, LLC, an OPEN Health company, and was funded by Allergan Aesthetics, an AbbVie Company. The authors report no other conflicts of interest in this work.

\section{References}

1. Goodman M, Adams N, Corneil T, Kreukels B, Motmans J, Coleman E. Size and distribution of transgender and gender nonconforming populations: a narrative review. Endocrinol Metab Clin North Am. 2019;48(2):303-321. doi:10.1016/j.ecl.2019.01.001

2. Lai YC, Kazlouskaya M, Kazlouskaya V. Historical and current state of dermatologic care for sexual and gender minority populations. Dermatol Clin. 2020;38(2):177-183. doi:10.1016/j.det.2019.10.001

3. Ginsberg BA. Dermatologic care of the transgender patient. Int $J$ Womens Dermatol. 2017;3(1):65-67. doi:10.1016/j. ijwd.2016.11.007

4. Ginsberg BA, Calderon M, Seminara NM, Day D. A potential role for the dermatologist in the physical transformation of transgender people: a survey of attitudes and practices within the transgender community. $J$ Am Acad Dermatol. 2016;74(2):303-308. doi:10.1016/j. jaad.2015.10.013

5. Dhingra N, Bonati LM, Wang EB, Chou M, Jagdeo J. Medical and aesthetic procedural dermatology recommendations for transgender patients undergoing transition. $J$ Am Acad Dermatol. 2019;80:1712-1721. doi:10.1016/j.jaad.2018.05.1259

6. Hicks KE, Thomas JR. The changing face of beauty: a global assessment of facial beauty. Otolaryngol Clin North Am. 2020;53 (2):185-194. doi:10.1016/j.otc.2019.12.005

7. MacGregor JL, Chang YC. Minimally invasive procedures for gender affirmation. Dermatol Clin. 2020;38(2):249-260. doi:10.1016/j. det.2019.10.014

8. Galupo MP, Lomash E, Mitchell RC. "All of my lovers fit into this scale": sexual minority individuals' responses to two novel measures of sexual orientation. J Homosex. 2017;64(2):145-165. doi:10.1080/ 00918369.2016 .1174027 
9. Ascha M, Swanson MA, Massie JP, et al. Nonsurgical management of facial masculinization and feminization. Aesthet Surg J. 2019;39 (5):NP123-NP137. doi:10.1093/asj/sjy253

10. Marshall Z, Welch V, Minichiello A, Swab M, Brunger F, Kaposy C. Documenting research with transgender, nonbinary, and other gender diverse (trans) individuals and communities: introducing the global trans research evidence map. Transgend Health. 2019;4(1):68-80. doi:10.1089/trgh.2018.0020

11. Garrett MB. Working with transgender individuals in case management practice. Prof Case Manag. 2018;23(1):19-24. doi:10.1097/ NCM.0000000000000251

12. Sullivan P, Trinidad J, Hamann D. Issues in transgender dermatology: a systematic review of the literature. J Am Acad Dermatol. 2019;81 (2):438-447. doi:10.1016/j.jaad.2019.03.023

13. Ufomata E, Eckstrand KL, Spagnoletti C, et al. Comprehensive curriculum for internal medicine residents on primary care of patients identifying as lesbian, gay, bisexual, or transgender. MedEdPORTAL. 2020;16:10875. doi:10.15766/mep 2374-8265.10875

14. Marks DH, Awosika O, Rengifo-Pardo M, Ehrlich A. Dermatologic surgical care for transgender individuals. Dermatol Surg. 2019;45 (3):446-457. doi:10.1097/DSS.0000000000001718

15. Carruthers JD, Glogau RG, Blitzer A. Advances in facial rejuvenation: botulinum toxin type A, hyaluronic acid dermal fillers, and combination therapies - consensus recommendations. Plast Reconstr Surg. 2008;121(supp15):5S-30S. doi:10.1097/PRS.0b013e31816 de8d0

16. Whitaker LA, Morales L Jr, Farkas LG. Aesthetic surgery of the supraorbital ridge and forehead structures. Plast Reconstr Surg. 1986;78(1):23-32. doi:10.1097/00006534-198607000-00003

17. Berli JU, Capitán L, Simon D, Bluebond-Langner R, Plemons E, Morrison SD. Facial gender confirmation surgery-review of the literature and recommendations for Version 8 of the WPATH Standards of Care. Int $J$ Transgend. 2017;18(3):264-270. doi:10.1080/15532739.2017.1302862

18. Deschamps-Braly JC. Facial gender confirmation surgery: facial feminization surgery and facial masculinization surgery. Clin Plast Surg. 2018;45(3):323-331. doi:10.1016/j.cps.2018.03.005

19. Morrison SD, Vyas KS, Motakef S, et al. Facial feminization: systematic review of the literature. Plast Reconstr Surg. 2016;137 (6):1759-1770. doi:10.1097/PRS.0000000000002171

20. de Maio M. Ethnic and gender considerations in the use of facial injectables: male patients. Plast Reconstr Surg. 2015;136 (supp15):40S-43S. doi:10.1097/PRS.0000000000001729

21. Fernbach M. Recommendations for age and sex diagnoses of skeletons. J Hum Evol. 1980;9(7):517-549.

22. Goldstein SM, Katowitz JA. The male eyebrow: a topographic anatomic analysis. Ophthal Plast Reconstr Surg. 2005;21(4):285-291. doi:10.1097/01.iop.0000169253.68675.18

23. Dempf R, Eckert AW. Contouring the forehead and rhinoplasty in the feminization of the face in male-to-female transsexuals. $J$ Craniomaxillofac Surg. 2010;38(6):416-422. doi:10.1016/j. jcms.2009.11.003

24. Garvin HM, Ruff CB. Sexual dimorphism in skeletal browridge and chin morphologies determined using a new quantitative method. $\mathrm{Am}$ J Phys Anthropol. 2012;147(4):661-670. doi:10.1002/ajpa.22036

25. Gunter JP, Antrobus SD. Aesthetic analysis of the eyebrows. Plast Reconstr Surg. 1997;99(7):1808-1816. doi:10.1097/00006534199706000-00002

26. Freund RM, Nolan WB 3rd. Correlation between brow lift outcomes and aesthetic ideals for eyebrow height and shape in females. Plast Reconstr Surg. 1996;97(7):1343-1348. doi:10.1097/00006534199606000-00003

27. Rohrich RJ, Janis JE, Kenkel JM. Male rhinoplasty. Plast Reconstr Surg. 2003;112(4):1071-1085; quiz 1086. doi:10.1097/01. PRS.0000076201.75278.BB
28. Koudelova J, Bruzek J, Caganova V, Krajicek V, Veleminska J. Development of facial sexual dimorphism in children aged between 12 and 15 years: a three-dimensional longitudinal study. Orthod Craniofac Res. 2015;18(3):175-184. doi:10.1111/ocr.12096

29. Wysong A, Joseph T, Kim D, Tang JY, Gladstone HB. Quantifying soft tissue loss in facial aging: a study in women using magnetic resonance imaging. Dermatol Surg. 2013;39(12):1895-1902. doi:10.1111/dsu. 12362

30. Wysong A, Kim D, Joseph T, MacFarlane DF, Tang JY, Gladstone HB. Quantifying soft tissue loss in the aging male face using magnetic resonance imaging. Dermatol Surg. 2014;40 (7):786-793. doi:10.1111/dsu.0000000000000035

31. Donnelly SM, Hens SM, Rogers NL, Schneider KL. Technical note: a blind test of mandibular ramus flexure as a morphologic indicator of sexual dimorphism in the human skeleton. Am J Phys Anthropol. 1998;107(3):363-366. doi:10.1002/(SICI)1096-8644(199811) 107:3<363::AID-AJPA11>3.0.CO;2-Y

32. Thayer ZM, Dobson SD. Sexual dimorphism in chin shape: implications for adaptive hypotheses. Am J Phys Anthropol. 2010;143 (3):417-425. doi:10.1002/ajpa.21330

33. Cohen BE, Bashey S, Wysong A. Literature review of cosmetic procedures in men: approaches and techniques are gender specific. Am J Clin Dermatol. 2017;18(1):87-96. doi:10.1007/s40257-016-0237-x

34. Scherer MA. Specific aspects of a combined approach to male face correction: botulinum toxin A and volumetric fillers. $J$ Cosmet Dermatol. 2016;15(4):566-574. doi:10.1111/jocd.12247

35. Spiegel JH. Facial feminization for the transgender patient. J Craniofac Surg. 2019;30(5):1399-1402. doi:10.1097/ SCS.0000000000005645

36. Talakoub L, Wesley NO. Differences in perceptions of beauty and cosmetic procedures performed in ethnic patients. Semin Cutan Med Surg. 2009;28(2):115-129. doi:10.1016/j.sder.2009.05.001

37. Kuroe K, Rosas A, Molleson T. Variation in the cranial base orientation and facial skeleton in dry skulls sampled from three major populations. Eur J Orthod. 2004;26(2):201-207. doi:10.1093/ejo/ 26.2.201

38. Blumenfeld J. Racial identification in the skull and teeth. Totem Univ West Ontario J Anthropol. 2000;8(1):4.

39. Samizadeh S, Wu W. Ideals of facial beauty amongst the Chinese population: results from a large national survey. Aesthetic Plast Surg. 2018;42(6):1540-1550. doi:10.1007/s00266-018-1188-9

40. Ruoss AV, Short WR, Kovarik CL. The patient's perspective: reorienting dermatologic care for lesbian, gay, bisexual, transgender, and queer/questioning patients. Dermatol Clin. 2020;38(2):191-199. doi:10.1016/j.det.2019.10.003

41. Philipp-Dormston WG, Eccleston D, De Boulle K, Hilton S, van den Elzen H, Nathan M. A prospective, observational study of the volumizing effect of open-label aesthetic use of Juvéderm ${ }^{\circledR}$ VOLUMA $^{\circledR}$ with lidocaine in mid-face area. J Cosmet Laser Ther. 2014;16 (4):171-179. doi:10.3109/14764172.2014.910079

42. Fink B, Neave N. The biology of facial beauty. Int J Cosmet Sci. 2005;27(6):317-325. doi:10.1111/j.1467-2494.2005.00286.x

43. de Maio M, Swift A, Signorini M, Fagien S. Facial assessment and injection guide for botulinum toxin and injectable hyaluronic acid fillers: focus on the upper face. Plast Reconstr Surg. 2017;140 (2):265e-276e. doi:10.1097/PRS.0000000000003544

44. Gart MS, Gutowski KA. Overview of botulinum toxins for aesthetic uses. Clin Plast Surg. 2016;43(3):459-471. doi:10.1016/j. cps.2016.03.003

45. Qaqish C. Botulinum toxin use in the upper face. Atlas Oral Maxillofac Surg Clin North Am. 2016;24(2):95-103. doi:10.1016/j. cxom.2016.05.006

46. Lee DH, Jin SP, Cho S, et al. RimabotulinumtoxinB versus onabotulinumtoxinA in the treatment of masseter hypertrophy: a 24-week double-blind randomized split-face study. Dermatology. 2013;226(3):227-232. doi:10.1159/000349984 
47. Haworth RD. Customizing perioral enhancement to obtain ideal lip aesthetics: combining both lip voluming and reshaping procedures by means of an algorithmic approach. Plast Reconstr Surg. 2004;113 (7):2182-2193. doi:10.1097/01.PRS.0000122546.90916.B4

48. Dallara JM, Baspeyras M, Bui P, Cartier H, Charavel MH, Dumas L. Calcium hydroxylapatite for jawline rejuvenation: consensus recommendations. J Cosmet Dermatol. 2014;13(1):3-14. doi:10.1111/ jocd. 12074
49. Buckingham ED, Glasgold R, Kontis T, et al. Volume rejuvenation of the lower third, perioral, and jawline. Facial Plast Surg. 2015;31 (1):70-79. doi:10.1055/s-0035-1544945

Clinical, Cosmetic and Investigational Dermatology

\section{Publish your work in this journal}

Clinical, Cosmetic and Investigational Dermatology is an international, peer-reviewed, open access, online journal that focuses on the latest clinical and experimental research in all aspects of skin disease and cosmetic interventions. This journal is indexed on CAS

Submit your manuscript here: https://www.dovepress.com/clinical-cosmetic-and-investigational-dermatology-journal
The manuscript management system is completely online and includes a very quick and fair peer-review system, which is all easy to use. Visit http://www.dovepress.com/testimonials.php to read real quotes from published authors. 